\title{
Nos vestígios e registros do saber: arquivos, patrimônio e pesquisas educacionais
}

\author{
Marcelo de Sousa Neto \\ Pedro Pio Fontineles Filho ${ }^{\text {II }}$
}

\begin{abstract}
Resumo: o presente estudo tem o objetivo principal de analisar as interconexões teórico-metodológicas entre arquivos, patrimônio e educação no processo de conhecimento das sociedades. Os arquivos assumem papel que vão além da prática de catalogação de registros, visto que são expressões de realidades políticas, econômicas, sociais e culturais que os engendram. Metodologicamente, o estudo faz um percurso acerca das principais perspectivas que envolvem as dimensões do arquivo como instrumento para as propostas educacionais, inclusive na formação de professorespesquisadores. Além disso, propõe reflexões acerca de tal percurso, realizando inferências sobre as perspectivas da prática dos arquivos no Brasil, em suas reverberações na memória e no patrimônio. Como bases teóricas, recorreu aos lastros deixados por Bloch (1981), Demo (2003), Derrida (2001), para pensar história, arquivos, patrimônio e educação. Assim, considera-se, de antemão, que os arquivos são instâncias que (re) criam a realidade, bem como são indícios históricos de memória, patrimônio e educação.
\end{abstract}

Palavras-chave: História. Arquivo. Memória. Patrimônio.

\section{On traces and records of knowing: archives, heritage and education researches}

\begin{abstract}
: the present study has the main aim to analyze the theoretical and methodological interconections among archives, heritage and education on knowledge proccess of societies. Archives take the position besides the practice of cataloging of records, because they are expression of policy, economic, social and cultural realities that impulse them. As methody, the study did a route about the main perspectives that link dimensions of the archive as instrument to the education purposes, including the teachers and researchers formation. Besides that, it purposes reflexions about such route, thingking of perspectives of archive practice in Brazil, in its ressonances on memory and heritage. As theoretical basis, it used the weights left by Bloch (1981), Demo (2003), Derrida (2001), to think history, archives, heritage and education. Thus it's considered, beforehand, that the archives are instances that (re) create the reality, as well as they are historical evidence of memory, heritage and education.
\end{abstract}

Keywords: History. Archive. Memory. Heritage.

Artigo recebido em 21/12/2015 e aprovado em 05/01/2016. 


\title{
NOS VESTÍGIOS E REGISTROS DO SABER: ARQUIVOS, PATRIMÔNIO E PESQUISAS EDUCACIONAIS
}

\author{
MARCELO DE SOUSA NETO E PEDRO PIO FONTINELES FILHO
}

\section{Introdução}

\begin{abstract}
[...] os documentos não surgem aqui ou acolá por artes mágicas. A sua presença ou a sua ausência em determinado fundo de arquivo, em determinada biblioteca, em determinado terreno, dependem de causas humanas que de maneira alguma escapam à análise, e os problemas que a sua transmissão levanta, longe de se encontrarem somente ao alcance de exercícios técnicos, respeitam, eles mesmos, ao mais íntimo da vida do passado, porque aquilo que se encontra afinal em jogo não é nem mais nem menos do que passagem da memória das coisas através de gerações ${ }^{\mathrm{III}}$.
\end{abstract}

“Os arquivos são o ser encarnado da factualidade". É assim que Lévi-Strauss ${ }^{\mathrm{IV}}$ se refere ao fato de que os arquivos dão corporeidade aos fatos e aos acontecimentos, pelo menos em uma fração de sua existência. Pelo caráter lacunar da própria história, os arquivos se comportam como mais um espaço voltado para promover a ligação dos retalhos da história, fazendo com que o passado chegue ao presente por meio dos vestígios catalogados. Para Lévi-Strauss, nesse sentido, uma das maiores virtudes dos arquivos é a sua capacidade de colocar aos observadores, pesquisadores em contato com os regimes de historicidade. Com as camadas de verdades e discursos que são incorporados nas tessituras do arquivo e de seu acervo.

Por esse diapasão, as práticas voltadas às pesquisas, sobretudo no que se refere aos registros escritos, gráficos e imagéticos, têm ganhado relevante espaço no seio dos estudos acadêmico-científicos. A valorização dos arquivos, não somente como depósitos de documentos, mas como reveladores de memórias, histórias, culturas e práticas socioculturais, deve ser destacada em seus vários alcances. Isso porque não apenas os historiadores e/ou arquivistas são os únicos responsáveis ou detentores dos registros que se encontram nos arquivos, sobretudo aqueles considerados públicos. Como salientou Marc Bloch, "a passagem da memória" não está a cargo de uma área isolada e específica, visto que a disposição de documentos não se dá a partir de interesses harmônicos e homogêneos. A maneira e as condições como os documentos chegam e permanecem nos arquivos dão indícios de inúmeras práticas de produção, circulação, consumo e apropriação dos registros e dos fatos. Os arquivos permitem traçar os rastros das trilhas da educação em suas vinculações com aspectos políticos, econômicos, sociais, culturais, bem como as relações de gênero e as memórias e identidades.

Naquilo que se costumou chamar de "pesquisas educacionais" há um leque muito grande de perspectivas, de posicionamentos, de questionamentos e, de certa forma, poucas respostas. Pode-se dizer que as respostas até existem, mas não no sentido de se pretenderem definitivas, o que é importante, sobretudo quando se trata de produção de conhecimento orientado e voltado para as questões humanas, históricas e socioculturais. O que, também, não é o propósito deste estudo elencar respostas sobre a liquidez conceitual dessas práticas. O que se pretende destacar é que, com as muitas possibilidades de metodologias e de interpretação, as pesquisas educacionais não se restringem a uma área específica do saber. Basta se questionar se há uma pesquisa 


\section{NOS VESTÍGIOS E REGISTROS DO SABER: ARQUIVOS, PATRIMÔNIO E PESQUISAS EDUCACIONAIS}

\section{MARCELO DE SOUSA NETO E PEDRO PIO FONTINELES FILHO}

educacional específica, o que se chega a uma conclusão prévia de que não há. O que existem são pesquisas que se debruçam sobre temáticas da educação e, por esse sentido genérico, são consideradas de pesquisas educacionais. Mas não um campo ou uma área específica, visto que as metodologias imprimem diálogo entre as diferentes áreas.

Tomar os arquivos públicos como possibilidade de se implementar práticas de pesquisas educacionais, como a própria educação patrimonial, é considerar o sentido ativo do processo de formação dos indivíduos. Não somente a formação advinda da instrução oficial, mas a formação que se amalgama com a conscientização, da memória e das identidades. Nesse sentido, o arquivo como lugar de pesquisa é indispensável ao processo da pesquisa educacional, visto que "educar pela pesquisa tem como condição primeira que o profissional da educação seja pesquisador, ou seja, maneje a pesquisa como princípio científico e educativo e a tenha como atitude cotidiana" ${ }^{\mathrm{V}}$. Para Demo, é necessário mesclar a "atitude cotidiana" com a "atitude em busca de resultado específico" da pesquisa. Os arquivos públicos devem ser inseridos na pesquisa educacional como mais um instrumento no processo de formação, tanto de professores como de alunos, pois, como resultado máximo, se chama à emancipação pela criticidade e cidadania.

Conhecer os diferentes patrimônios é o primeiro passo para a efetivação da educação patrimonial, pois como educar sem antes conhecer? Como exigir uma consciência patrimonial se as pessoas não se sentem identificadas como tal patrimônio? Como haver tal identificação se as memórias parecem não fazer sentido ou mesmo não existir para a população ou para um grupo? As pesquisas educacionais devem lançar esses e muitos outros questionamentos para sustentar seus objetivos de construção de conhecimento.

Desse modo, as pesquisas educacionais não podem ser pensadas de forma hermética. Não se pode achar que tais pesquisas estão unicamente voltadas para a "história da educação", que, por sua vez, também remete a labirintos de conceituação e de pesquisa. Assim, é mister dizer que essas pesquisas consideradas "educacionais" não se limitam à área da Pedagogia, visto que a Educação, em seu sentido amplo, é objeto de interesse de inúmeras outras áreas do saber e do conhecimento.

Isto posto, é indispensável dizer que o objetivo principal do presente estudo é discutir sobre a importância das inter-relações de três elementos fundamentais para a compreensão da sociedade: arquivos, patrimônio e educação. Os arquivos se constituem como instrumentos para o encaminhamento de pesquisas educacionais, que vão além dos tratados de teorias pedagógicas. As reflexões do presente trabalho visam contribuir para os debates acerca dos arquivos públicos como patrimônio social carente de maior atenção das políticas públicas e ações estratégicas do Estado. A partir da revisão da literatura acerca do tema, realizou-se a crítica dos desafios enfrentados pelos arquivos públicos no país e a necessidade do diálogo com novas tecnologias como forma de preservar seus acervos e fortalecer a função social desempenhada pelos arquivos públicos. As pesquisas educacionais são aqui entendidas como um leque amplo de busca de vestígios e registros que contemplem elementos da educação, em seus meandros com a memória, o patrimônio e as identidades. Daí os arquivos serem espaço de intersecção dessas categorias.

\section{Nos percursos do arquivo: princípios da pesquisa educacional}




\title{
NOS VESTÍGIOS E REGISTROS DO SABER: ARQUIVOS, PATRIMÔNIO E PESQUISAS EDUCACIONAIS
}

\author{
MARCELO DE SOUSA NETO E PEDRO PIO FONTINELES FILHO
}

Tornou-se urgente constituir um arquivo coletivo da pesquisa em educação e definir uma ou várias frentes de pesquisa ${ }^{V I}$.

Pluralidade e variedade de temáticas coexistem nos arquivos públicos. Tal pluralidade se dá, em grande medida, pelas origens, fins e destinos de cada documento constante nas gavetas, armários e prateleiras dos arquivos. A variedade se relaciona, entre outros aspectos, aos tipos e aos gêneros dos documentos. Além disso, a pluralidade e a variedade coadunam-se no momento em que novos olhares, novos interesses e novas metodologias são lançados ao arcabouço documental do arquivo público. Vale ressaltar que o próprio prédio, que abriga determinado arquivo, se constitui como documento, no sentido de ser um objeto à espera de ser construído, desconstruído e reconstruído, mediante a infinitude de questionamentos que a ele se destinam. Nesse sentido, é fulcral dizer que

\begin{abstract}
Em nossos dias, já ninguém duvida de que a história do mundo deve ser reescrita de tempos em tempos. Esta necessidade não decorre, contudo, da descoberta de numerosos fatos até então desconhecidos, mas do nascimento de opiniões novas, do fato de que companheiro do tempo que corre para a foz chega a pontos de vista de onde pode deitar um olhar novo sobre o passado $^{\text {VII }}$.
\end{abstract}

É já praticamente consenso de que, na historiografia atual, há inúmeras direções teórico-metodológicas que abrem espaço para temas e objetos outrora relegados a segundo plano ou mesmo esquecidos. Para tal, as fontes de arquivo, como jornais, periódicos e revistas têm sido (re)visitadas continuamente. Ao eleger ou determinar que esses documentos se tornem fontes e objetos de pesquisa, se está ampliando o universo das fontes, com o intuito de acessar os dispositivos e práticas discursivas que configuram as especificidades dos campos de saber.

Os arquivos assumem papel essencial na integração entre educação e patrimônio, pois, a partir do contato com o manancial dos arquivos, professores, estudantes, pesquisadores, intelectuais podem desenvolver suas funções e profissões no sentido social que elas exigem. Sendo assim, o patrimônio cultural e a educação para o patrimônio cultural são encaradas como um fio condutor para o despertar de posicionamentos e posturas de preservação de inúmeros aspectos e traços históricos, social e culturais. Não obstante, a educação patrimonial

\footnotetext{
Trata-se de um processo permanente e sistemático de trabalho educacional centrado no Patrimônio Cultural como fonte de conhecimento individual e coletivo. A partir da experiência e do contato direto com as evidências e manifestações da cultural, em todos seus múltiplos aspectos, sentidos e significados, o trabalho de educação patrimonial busca levar as crianças e adultos a um processo ativo de conhecimento, apropriação e valorização da herança cultural da comunidade, capacitando-os para um melhor usufruto destes bens, e propiciando a geração e a produção de novos conhecimentos, num processo contínuo de criação cultural ${ }^{\mathrm{VIII}}$.
} 


\title{
NOS VESTÍGIOS E REGISTROS DO SABER: ARQUIVOS, PATRIMÔNIO E PESQUISAS EDUCACIONAIS
}

\author{
MARCELO DE SOUSA NETO E PEDRO PIO FONTINELES FILHO
}

Por esse diapasão, a educação patrimonial, tomando os arquivos públicos como foco, pretende ir além da pesquisa educacional como acúmulo de informação. Ela se envereda pelos meandros da memória, pois não se pode falar de educação patrimonial sem pensar nos arcabouços da memória, visto que

\begin{abstract}
Memória, história: longe de ser sinônimos, tomamos consciência de que as opõe. A memória é a vida, sempre levada por grupos vivos e, nesse sentido, ela está em evolução permanente, aberta à dialética da lembrança e da amnésia, inconsciente de suas sucessivas deformações vulneráveis a todas as utilizações e manipulações, suscetíveis de longas latências e súbitas revitalizações. A história é a reconstrução problemática e incompleta do que não é mais. A memória é um fenômeno sempre atual, um vínculo vivido no presente eterno; a história, uma representação do passado. Por ser efetiva e mágica, a memória só se contenta com detalhes que a confortam: ela se alimenta de lembranças opacas, globais ou flutuantes, particulares ou simbólicas, sensível a todas as transferências, censuras, telas ou projeções. A história, porque operação intelectual e laicizante, chama análise e discurso crítico. A memória instala a lembrança no sagrado, a história a desaloja, ela sempre torna prosaico ${ }^{\mathrm{IX}}$.
\end{abstract}

A pesquisa educacional que se propõe por meio dos arquivos é diretamente ligada à promoção de atitudes emancipatórias de conscientização. A educação patrimonial é voltada para a visualização e criação de memórias, de conhecimento e construção de identidades, de práticas, de fazeres e de saberes. Dessa maneira, como assevera Nora, a postura histórica, da pesquisa de maneira geral, não pode tomar os arquivos instalado no sagrado e, sim, desalojando-o, tornando-o prosaico.

O Arquivo, nas suas conexões com as temporalidades, com os tempos ligados entre o passado e o presente, se insere na potência e no desejo do futuro. Por essa potência, o arquivo assume a autoridade do lugar e da prática que pretende gestar e gerir as memórias e as identidades. $\mathrm{O}$ arquivo que, a priori, parece engessar o tempo, se manifesta como o âmbito das pluralidades, visto que está fadado, no sentido amplo, ao constante ato de (re) visitação e (re) interpretação de seu acervo. O que define tal pluralidade é exatamente as demandas que são oriundas dos olhares e inquietações de cada tempo, sociedade e grupo. Na medida em que novas questões são postas ao universo do arquivo, novos textos e sentidos se formam. Assim, as memórias são revisitadas e isso permite que o processo de construção do conhecimento histórico continue em seu devir. Os arquivos, dessa maneira, não são lugares e espaços herméticos e inertes. São pulsantes tanto quanto pulsam os interesses de quem a ele recorre.

\section{Arquivos, patrimônio e políticas públicas: desafios e perspectivas no Brasil}

Pois o arquivo, se esta palavra ou esta figura se estabiliza em alguma significação, não será jamais a memória nem a anamneses em sua experiência espontânea, viva e interior. Bem ao contrário: o arquivo tem lugar em lugar da falta originária e estrutural da chamada memória ${ }^{X}$. 


\title{
NOS VESTÍGIOS E REGISTROS DO SABER: ARQUIVOS, PATRIMÔNIO E PESQUISAS EDUCACIONAIS
}

\author{
MARCELO DE SOUSA NETO E PEDRO PIO FONTINELES FILHO
}

As discussões a respeito da formação, manutenção e acesso aos arquivos públicos no Brasil tem, nas últimas décadas, ganho maior amplitude dentro do próprio repensar das fontes históricas e do fazer historiográfico. Seguindo as trilhas abertas sobre a temática, o presente texto objetiva ser uma reflexão comprometida com o olhar do usuário, o olhar do consumidor dos serviços dos arquivos públicos em seu cotidiano de pesquisas que, por algum tempo, passa a residir entre os papéis que outros decidiram que deveriam sobreviver às tiranias do esquecimento, preservados em arquivos para as novas gerações. Os desafios enfrentados pelos arquivos públicos brasileiros tem sido objeto de diversos diagnósticos nas últimas décadas, que denunciam a progressiva corrosão da situação arquivística, desde os acervos acumulados aos documentos em fase de produção, sinalizando para um verdadeiro caos informacional, agravados pela perda do controle dos acervos e a dificuldade de se acessar as informações ${ }^{X I}$.

Entretanto, aos nos debruçarmos sobre o estudo dos arquivos, a associação entre arquivos e memória representa tema recorrente, a qual Lodolini nos ajuda a entender essa associação, segundo o qual,

desde a mais alta Antigüidade, o homem demonstrou a necessidade de conservar sua própria 'memória' inicialmente sob a forma oral, depois sob a forma de graffiti e desenhos e, enfim, com o uso de um sistema codificado.... A memória assim registrada e conservada constituiu e constitui ainda a base de toda atividade humana: a existência de um grupo social seria impossível sem o registro da memória, ou seja, sem os arquivos ${ }^{\mathrm{XII}}$.

Os arquivos tornaram-se, então, local privilegiado da luta entre a memória e o esquecimento. Segundo Nora, esse é um local de encontro e conflito das duas formas de nossa memória contemporânea: "a memória vivida e a memória documental; a memória direta e a memória indireta; imediata e mediata; a memória do testemunho e a da história científica, a memória viva e a memória reconstruída, memória quente e memória fria" XIII.

A memória, transformada por sua passagem em história, permite, então, ainda conforme Nora $^{\mathrm{XIV}}$, o surgimento de uma memória arquivística, um gigantesco estoque material daquilo que nos é impossível lembrar, que procura bloquear o trabalho do esquecimento, fixando um estado de coisas, vestígios sacralizados e voluntariamente organizados de uma memória perdida. Entretanto, a transmissão e uso das informações contidas nesse estoque material, custodiados pelos arquivos, constitui-se cerne da discussão que ora apresentamos. No caso brasileiro, a Constituição Federal, a Lei ${ }^{\circ}$ 8.159, de 8 de janeiro de 1991 - dispõe sobre a política de arquivos públicos e privados - e a legislação complementar, representam instrumentos legais que garantem o acesso aos cidadãos dos documentos produzidos pela administração pública. No entanto, pensar os arquivos públicos e seu acesso deve extrapolar a questão jurídico-legal, considerando que o acesso jurídico à informação não se consolida sem o seu acesso intelectual $^{\mathrm{XV}}$.

Apesar de reconhecermos a importância do estabelecimento de instrumentos jurídicos de acesso à informação, devemos ter em vista os encaminhamentos que melhorem as condições de acesso aos arquivos públicos brasileiros, considerando que o 


\section{NOS VESTÍGIOS E REGISTROS DO SABER: ARQUIVOS, PATRIMÔNIO E PESQUISAS EDUCACIONAIS}

\section{MARCELO DE SOUSA NETO E PEDRO PIO FONTINELES FILHO}

acesso físico, garantido pelos aparelhos jurídicos, deve ser acompanhado do acesso intelectual aos acervos, o que não pode ser conseguido sem o auxílio de políticas públicas de informação consistentes.

Nesse sentido, muitos obstáculos não-legais podem ser destacados ao acesso à informação contida nos acervos dos arquivos. Entre esses, sobressaem-se a precária situação dos arquivos, privados da autoridade necessária para estabelecer as rotinas e normas da gestão de documentos para os órgãos da administração pública em sua esfera correspondente; a falta de espaço físico adequado para o recolhimento da documentação de valor permanente, e a falta de quadro de pessoal adequado ao preparo dos instrumentos de pesquisa necessários para garantir o pleno acesso aos documentos ${ }^{\mathrm{XVI}}$.

$\mathrm{O}$ acesso aos documentos de arquivo ainda são mais conturbados quando recortamos as nossas análises para a esfera dos municípios. Frente ao novo pacto federativo, firmado pela Constituição Federal de 1988, os municípios adquiriram um novo impulso como espaço privilegiado das relações entre Estado e cidadãos, a qual deveria também privilegiar o acesso às informações e documentos produzidos por este mesmo Estado. Diferente disso, o que se observa por todo o país é uma grande lacuna quanto ao acesso a dados sistematizados de arquivos municipais.

Devemos observar que a partir da década de 1950, os arquivos públicos passaram a ser considerados em todo o mundo como órgãos estratégicos na gerência das informações produzidas pelo Estado dentro dos princípios da gestão de documentos, identificados no elenco dos direitos humanos, relacionados ao direito à informação, à livre expressão, à liberdade de imprensa e suas implicações, mas também como uma forma de resguardar a memória de vários países dilacerados pelos dois conflitos mundiais. Entretanto, no Brasil ações nesse sentido ainda são muito tímidas, tomadas ainda por muitos como uma concessão do Estado e não como o direito do cidadão ${ }^{\text {VVII }}$, haja vista que os arquivos continuaram a ser tratados como propriedade do Estado e não da sociedade.

Nesse sentido, como uma concessão e não como um direito à informação, reservou-se aos arquivos públicos uma posição inferior na estrutura administrativa, privado de mecanismos que garantam seu papel institucional na implementação de uma política de arquivos e da gestão dos documentos produzidos. A própria inexistência de arquivos em muitas regiões do país representa obstáculo primeiro ao acesso à informação, condição mais alarmante ao que se refere a arquivos públicos municipais, restringindo o desenvolvimento de pesquisas que tratem desses locais pela impossibilidade de trabalho com as fontes.

Mesmo para os limitados arquivos existentes, o acesso à informação ganha outros entraves. As dificuldades de acesso às informações produzidas pelo Estado, no caso brasileiro, podem muito bem ser exemplificadas pela fragilidade dos arquivos municipais, entre os quais tomados apenas arquivos municipais de capitais do país, encontram-se cadastros no Arquivo Nacional e no Arquivo Geral da Cidade do Rio de Janeiro, informações sobre 11 arquivos, localizados nas cidades de Aracaju, Belo Horizonte, Fortaleza, Porto Alegre, Rio de Janeiro, Salvador, São Paulo, Vitória, Campo Grande, São Luís e Brasília XVIII.

O pequeno número de arquivos públicos, sejam municipais, estaduais ou federais, denota a pouca atenção disponibilizada pelo Estado à questão do tratamento adequado de seus arquivos e que, mesmo nos poucos existentes, ainda enfrentam problemas os mais sérios quanto à disponibilização de seus acervos pelas dificuldades estruturais a 


\section{NOS VESTÍGIOS E REGISTROS DO SABER: ARQUIVOS, PATRIMÔNIO E PESQUISAS EDUCACIONAIS}

\section{MARCELO DE SOUSA NETO E PEDRO PIO FONTINELES FILHO}

que estão sujeitos. Mas as dificuldades enfrentadas pelos arquivos encontram alguma ressonância na própria posição dos arquivos públicos na estrutura administrativa de estados e municípios que, em geral, encontram-se submetidas a outras secretarias ou instâncias administrativas, a exemplo das secretarias de cultura ou administração. Essa condição revela que os arquivos não são entendidos pelo Estado como um órgão de decisão administrativa, mas apenas como instância colaboradora ou consultiva.

A condição secundária dos arquivos na estrutura administrativas dos entes federados pode ainda ser demonstrada pela condição de que em sua maioria, se não em sua totalidade, os arquivos públicos no Brasil não contarem com orçamento próprio, dependendo absolutamente das decisões superiores para a obtenção de recursos ${ }^{\text {XIX }}$, impossibilitando muitas iniciativas que democratizem o acesso e preservem seus acervos. Essa condição de coadjuvante do cenário político-social de estados e municípios representa uma distorção da própria função moderna dos arquivos e cria obstáculos os mais severos à criação de uma política eficiente de arquivos, ao impedir que se estabeleçam protocolos a serem seguidos por todos os órgãos da administração pública.

A sobreposição de autoridades resulta, desta forma, em uma indefinição e limitação das atribuições e contribuições dos arquivos, conservando uma visão equivocada de que estes seriam responsáveis apenas dos arquivos de valor permanente ou "históricos" encaminhados pelas diversas instâncias da administração pública, geralmente preservando registros acerca das decisões de cunho político naquilo que historiadores como Marc Bloch e Lucian Febvre chamam de história evenementiele ou história dos eventos.

A falta de políticas públicas que beneficiem ou incentivem o trabalho das instituições arquivísticas, podem ser observadas no baixo número de recolhimentos dos arquivos de todo o país e que ainda revelam a falta de cuidado nos encaminhamentos das massas documentais, encaminhadas, geralmente, sem nenhuma organização e de forma assistemática o que resulta no empobrecimento dos acervos ${ }^{\mathrm{XX}}$. Nesse sentido, a existência de documentos não-identificados ou não-descritos nos acervos, significam não-acessíveis, o que fere um dos pressupostos básicos das instituições arquivísticas: o acesso à informação. Dessa forma, mesmo para a pesquisa histórica, as novas aquisições dos acervos tornam-se empobrecidas ${ }^{\mathrm{XI}}$. $\mathrm{Na}$ outra extremidade, faltam ações de preservação dos acervos já existentes, o que resulta também na perda de muitos acervos importantes.

A dificuldade de preservação/organização dos acervos encontra ressonância ainda em outro sério problema dos arquivos, a carência de recursos humanos qualificados, que por sua vez relaciona-se na inexistência das carreiras de arquivista e de técnico de arquivo e no reduzido número de cursos superiores de Arquivologia, localizados 2 (dois) no Rio de Janeiro, 1 (um) Rio Grande do Sul e 1 (um) Brasília. Os desafios que os arquivos do país são obrigados a enfrentar são de todas as montas, desde os mais básicos. Entre esses, podemos mesmo destacar os riscos de perda de acervo em virtude das precárias condições das instalações de alguns órgãos, considerando as peculiaridades e fragilidade dos acervos, o que tem clamado por medidas interventivas enérgicas e urgentes, justificadas pela condição de que muitos desses documentos custodiados são únicos e sua perda eliminaria qualquer possibilidade de acesso futuro.

Devemos observar, no entanto, que a comunidade acadêmica não pode ficar inerte frente ao descaso do Estado no que se refere às instituições arquivísticas, devendo, para 


\section{NOS VESTÍGIOS E REGISTROS DO SABER: ARQUIVOS, PATRIMÔNIO E PESQUISAS EDUCACIONAIS}

\section{MARCELO DE SOUSA NETO E PEDRO PIO FONTINELES FILHO}

tanto, apontar instrumentais necessários e suficientes no enfrentamento dos grandes desafios que se colocam. Esse processo de valorização dos arquivos perpassa, entre outros fatores, em uma tomada de posição dos próprios usuários que em sua inércia

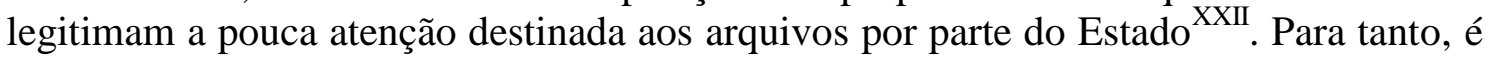
fundamental repensar também o próprio manuseio e conservação dos acervos e sua disponibilização por meio da circulação das pesquisas desenvolvidas como forma de dar visibilidade à sua importância.

A falta de iniciativas nesse sentido gerou um reduzido leque de usuários dos arquivos e é curioso notar como um espaço de prestação de serviços aos cidadãos de forma ampla, ficou restrito ao público acadêmico, um dos poucos a resistir ao esvaziamento dos arquivos, provocado pela reduzida atenção dedicada a eles. No cenário brasileiro, mesmo o Estado, produtor dos acervos custodiados, pouco se interessa ou retorna às informações arquivadas, entendendo, assim, arquivo como sinônimo de depósito. Os arquivos podem, entretanto, contar com poderosos aliados, por meio do diálogo com novas tecnologias, no sentido de criar produtos e instrumentais que permitam a preservação e acesso aos acervos, tornando os arquivos instituições ágeis com importância de decisão de políticas públicas.

Por meio do diálogo com essas novas tecnologias - tecnologias do acesso em rede, na qual sua expressão mais evidente é a Internet, e dos bancos de dados digitais começam a surgir arquivos capazes de gerar e gerir novos produtos, insumos e métodos de pesquisa que subsidiam o desenvolvimento de pesquisas e políticas públicas que contemplem os anseios e necessidades de seus usuários. Encontramo-nos hoje em uma fronteira do conhecimento que tem modificado as formas com que nos relacionamos com a informação e seu acesso e que continuam a receber o mesmo tratamento de meio século atrás. Devemos, então, estar abertos a repensarmos os arquivos e seu acesso, as quais novas tecnologias da informação constituem-se em vias das mais oportunas, que nos permitem em reduzidos espaços, acessíveis de qualquer parte do globo, e reduzidos investimentos, se comparados ao valor histórico-social dos arquivos, preservar toneladas de papéis em gramas de mídias/arquivos digitais.

Como exemplo de sucesso do diálogo com essas novas tecnologias pode ser citado o Projeto Resgate de Documentação Histórica Barão do Rio Branco (Projeto Resgate). Criado institucionalmente, em 1995, por meio de protocolo assinado entre as autoridades portuguesas e brasileiras no âmbito da Comissão Bilateral Luso-Brasileira de Salvaguarda e Divulgação do Patrimônio Documental (COLUSO), tem como objetivo principal disponibilizar documentos históricos relativos à História do Brasil existentes em arquivos de outros países, sobretudo Portugal e demais países europeus com os quais tivemos uma história colonial imbricada. Como resultado, encontramos disponíveis para consultas em rede ou em mídia digital (CD-Rom) de um maciço documental com mais de três séculos de documentos produzidos pela administração portuguesa relacionada ao Brasil ${ }^{\mathrm{XXIII}}$. Arquivos acessíveis por meio de ferramentas disponibilizadas por essas novas tecnologias da informação, representam instrumental no desenvolvimento de uma massa crítica de pesquisadores que terão à sua disposição um número maior de ferramentas e fontes ao desenvolvimento de seus trabalhos.

Cria-se, assim, uma relação de diálogo e acesso à informação, em que acervos distantes no espaço podem aproximar-se dos pesquisadores por meio de novos canais de comunicação. Para tanto, devemos ter em vista que o que qualifica o uso desses novos recursos tecnológicos são escolhas que perpassam pelo perfeito funcionamento das 


\section{NOS VESTÍGIOS E REGISTROS DO SABER: ARQUIVOS, PATRIMÔNIO E} PESQUISAS EDUCACIONAIS

\section{MARCELO DE SOUSA NETO E PEDRO PIO FONTINELES FILHO}

instituições arquivísticas e se inserem numa política de informação consistente, considerando que os instrumentais de tecnologia de ponta já são em alguma medida conhecidos, carecendo, no entanto, de políticas de fomento.

\section{Considerações Finais}

Resta-nos, então, ampliar a discussão e pensarmos os meios necessários e suficientes para tornar os arquivos um espaço partilhado, que consiga atender às novas demandas que se colocam, tornando o Estado inteligível ao cidadão, aquele que é alvo das decisões deste Estado e com ele deve colaborar e interferir em suas decisões.

Um caminho que tem contribuído para a ampliação desse vínculo entre sociedade e Estado é a consolidação de pesquisas de cunho histórico em níveis de graduação e pós-graduações em todo o país, e mais especificamente no Piauí, o que, além de gerar novas demandas por espaços de pesquisa mais acessíveis e portadores dos acervos específicos, fortalece o interesse da própria sociedade em buscar a conservação desses acervos como mecanismo de preservar a sua história e sua memória, em mais uma franca expressão da ressonância da atuação historiográfica. E se os historiadores são, como enuncia Paul Ricoeur XXIV " "guardiões do passado", nada mais natural que também sejamos guardiões dos espaços responsáveis por guardar, não o passado, mas fragmentos desse passado. Esse é, portanto, um de nossos desafios prementes, onde devemos nos apropriar dos arquivos públicos para torna-los objeto central de discussão numa clara parceria entre arquivos e sociedade de forma a permitir que este seja um espaço não apenas de coleta de fontes históricas, mas que se transforme em lócus privilegiado do próprio fazer historiográfico.

As pesquisas educacionais, em todos os seus sentidos e em todas as áreas do saber-conhecimento, devem levar em consideração, assim como na historiografia, a premissa de que as verdades são histórica, social e culturalmente construídas. Dessa maneira, os arquivos se apresentam como fontes inesgotáveis assim quanto forem inesgotáveis os questionamentos lançados aos documentos e registros que nele se encontram. É isso que impulsiona novas pesquisas e a contínua reescrita do passado. E a incursão pelos arquivos públicos, em especial, permite o contato mais acurado com as fontes que lá "habitam", esperando avidamente por visitas. O trato com tais fontes amplia os horizontes, para que as pesquisas educacionais não se restrinjam à história das ideias pedagógicas.

\section{Notas}

\footnotetext{
I Doutor em História pela Universidade Federal do Pernambuco. Professor do curso de História da Universidade Estadual do Piauí e do Programa de Pós-Graduação em História da Universidade Federal do Piauí.

II Doutor em História Social pela Universidade Federal do Ceará. Professor do curso de História da Universidade Estadual do Piauí.

III BLOCH, Marc. Uma Introdução à história. São Paulo: Brasiliense, 1981, p.66.
} 
${ }^{\text {IV }}$ LÉVI-STRAUSS, C. O pensamento selvagem. 2. ed. Campinas: Papirus, 1997, p. 269.

$\checkmark$ DEMO, P. Educar pela pesquisa. 6. ed. Campinas: Autores Associados, 2003, p. 02.

${ }^{V I}$ CHARLOT, Bernard. A pesquisa educacional entre conhecimentos, políticas e práticas: especificidades e desafios de uma área de saber. In: Revista Brasileira de Educação, v.11, n.31, p.07-18, Jan/Abril. Rio de Janeiro, 2006, p. 18.

VII GOETHE, J. Companheiros de viagem: Goethe e Schiller. São Paulo: Nova Alexandria, 1993, p. 104.

${ }^{\mathrm{VIII}}$ HORTA, Maria de Lourdes Parreira; GRUMBERG, Evelina; MONTEIRO, Adriane. Guia Básico de

Educação Patrimonial. Petrópolis: IPHAN, Museu Imperial, 2003, p. 03.

${ }^{\mathrm{IX}}$ NORA, Pierre. apud DOSSE, F. A história. Bauru: Edusc, 2003, p. 282.

${ }^{x}$ DERRIDA, J. Mal de arquivo: uma impressão freudiana. Rio de Janeiro: Relume Dumará, 2001. p. 22.

${ }^{\mathrm{XI}}$ SOUZA, Renato Tarcísio Barbosa de. Arquivos administrativos e massas documentais acumuladas: busca de novas soluções para velhos problemas. Brasília. Dissertação de Mestrado de Ciência da Informação e Documentação. Universidade de Brasília, 1995.

${ }^{X I I}$ LODOLINI, Elio. apud. JARDIM, José Maria. O acesso à informação arquivística no Brasil: problemas de acessibilidade e disseminação. Revista Ciência da Informação, 2009, p.04.

XIII NORA, Pierre. Entre memória e história: a problemática dos lugares. Revista do Programa de Estudos Pós-Graduados em História e do Departamento de História. São Paulo, n. 10, dez, 1993, p. 48)

XIV Idem.

$\mathrm{xV}$ JARDIM. Idem.

${ }^{\mathrm{XVI}}$ FONSECA, Maria Odila. Direito à informação: acesso aos arquivos públicos municipais. Rio de Janeiro. Instituto Brasileiro de Informação em Ciência e Tecnologia/Universidade Federal do Rio de Janeiro [Dissertação de Mestrado], 1996.

XVII Idem.

XvIII Idem.

XIX Idem.

xx CÔRTES, Maria Regina Persechini Armond. Arquivo Público e Informação: acesso à informação nos arquivos públicos estaduais do Brasil. Mestrado em Ciência da Informação. Escola de Biblioteconomia da Universidade Federal de Minas Gerais, 1996.

XXI FONSECA. Idem.

XXII Idem.

XXIII SOUSA NETO, Marcelo de. Entre vaqueiros e fidalgos: sociedade, política e educação no Piauí (1820-1850). Teresina: Fundação Monsenhor Chaves, 2013.

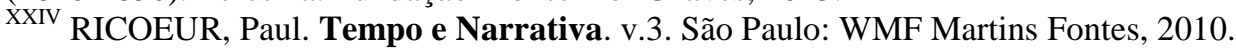

\section{Referências Bibliográficas}

BLOCH, Marc. Uma Introdução à história. São Paulo: Brasiliense, 1981.

BRASIL. Constituição da República Federativa do Brasil. Brasília: Senado Federal, 1988.

BRASIL. Decreto n. 2134, de 24 de janeiro de 1997. Regulamenta o art. 23 da Lei no 8.159, de 8 de janeiro de 1991, que dispõe sobre a categoria dos documentos públicos sigilosos e o acesso a eles, e dá outras providências. Diário Oficial da República Federativa do Brasil. Brasília, 27 de janeiro de 1997. Seção I.

BRASIL. Lei n. 8159, de 09 de janeiro de 1991. Dispõe sobre a política nacional de arquivos públicos e privados e dá outras providências. Diário Oficial da República Federativa do Brasil. Brasília, v.29, n.6, p. 455, jan. 1991, Seção I. 
CHARLOT, Bernard. A pesquisa educacional entre conhecimentos, políticas e práticas: especificidades e desafios de uma área de saber. In: Revista Brasileira de Educação, v.11, n.31, p.07-18, Jan/Abril. Rio de Janeiro, 2006.

CÔRTES, Maria Regina Persechini Armond. Arquivo Público e Informação: acesso à informação nos arquivos públicos estaduais do Brasil. Mestrado em Ciência da Informação. Escola de Biblioteconomia da Universidade Federal de Minas Gerais, 1996.

DEMO, P. Educar pela pesquisa. 6. ed. Campinas: Autores Associados, 2003.

DERRIDA, J. Mal de arquivo: uma impressão freudiana. Rio de Janeiro: Relume Dumará, 2001.

DOSSE, F. A história. Bauru: Edusc, 2003.

FONSECA, Maria Odila. Direito à informação: acesso aos arquivos públicos municipais. Rio de Janeiro. Instituto Brasileiro de Informação em Ciência e Tecnologia/Universidade Federal do Rio de Janeiro [Dissertação de Mestrado], 1996.

GOETHE, J. Companheiros de viagem: Goethe e Schiller. São Paulo: Nova Alexandria, 1993.

HORTA, Maria de Lourdes Parreira; GRUMBERG, Evelina; MONTEIRO, Adriane. Guia Básico de Educação Patrimonial. Petrópolis: IPHAN, Museu Imperial, 2003.

JARDIM, José Maria. A invenção da memória nos arquivos públicos. Ciência da Informação, $\quad$ v. $25, \quad$ n. $2, \quad 1995 . \quad$ Disponível em: www.ibict.br/cionline/include/getdoc.php? $\mathrm{id}=818 \&$ article $=480 \& \operatorname{mode}=$ pdf

JARDIM, José Maria. O acesso à informação arquivística no Brasil: problemas de acessibilidade e disseminação. s/e, 2009.

LÉVI-STRAUSS, C. O pensamento selvagem. 2. ed. Campinas: Papirus, 1997.

NORA, Pierre. Entre memória e história: a problemática dos lugares. Revista do Programa de Estudos Pós-Graduados em História e do Departamento de História. São Paulo, n. 10, dez, 1993.

RICOEUR, Paul. Tempo e Narrativa. v.3. São Paulo: WMF Martins Fontes, 2010.

SOUSA NETO, Marcelo de. Entre vaqueiros e fidalgos: sociedade, política e educação no Piauí (1820-1850). Teresina: Fundação Monsenhor Chaves, 2013.

SOUZA, Renato Tarcísio Barbosa de. Arquivos administrativos e massas documentais acumuladas: busca de novas soluções para velhos problemas. Brasília. Dissertação de Mestrado de Ciência da Informação e Documentação. Universidade de Brasília, 1995. 